\title{
Outcome After Mitral Valve Repair Or Replacement For Non-Ischemic Mitral Regurgitation: A System Review And Meta-Analysis
}

\section{Qianqian Fan}

Huazhong University of Science and Technology

\section{Xiaoguang Li}

Huazhong University of Science and Technology

\section{Guilan Cao}

Huazhong University of Science and Technology Tongji Medical College First Clinical College: Wuhan Union Hospital

\section{Puliang Yu}

Wuhan University of Science and Technology

\section{Fengxiao Zhang ( $\square$ xiaoyou_321@foxmail.com )}

Huazhong University of Science and Technology Tongji Medical College First Clinical College: Wuhan Union Hospital https://orcid.org/0000-0002-5109-4196

\section{Research Article}

Keywords: Non-ischemic mitral regurgitation, Mitral valve repair, Mitral valve replace, Meta-analysis

Posted Date: May 10th, 2021

DOl: https://doi.org/10.21203/rs.3.rs-371356/v1

License: (9) This work is licensed under a Creative Commons Attribution 4.0 International License. Read Full License 


\section{Abstract}

Background: Mitral regurgitation (MR) is a rather common valvular heart disease. The purpose of this meta-analysis is to compare the outcomes, and complications of mitral valve replacement (MVR) with surgical mitral valve repair (MVr) of non-ischemic MR (NIMR).

Methods: MEDLINE, EMBASE, and the Cochrane Central Register of Controlled Trials were searched through Oct 2020. 4834 studies were reviewed, and only 20 studies enrolling a total of 21,898 patients with NIMR were included. Eligible studies were enrolling patients with MR and reporting early (30-day or in-hospital) or late all-cause mortality. For each study, data regarding all-cause mortality and incidence of reoperation and operative complications in both groups were used to generate odds ratios (ORs) or hazard ratios (HRs).

Results: The pooled analysis showed that lower age, rate of women and incident of hypertension, significantly rates of diabetes and atrial fibrillation in MVR group than MVr group, no significant difference in rates of pre-operative left ventricle ejection fraction (LVEF) and heart failure. Subjects in $\mathrm{MVr}$ group is slightly less than MVR group. Replacement of MR has significantly increased risk of early and late mortality. Moreover, the rate of re-operation and post-operative MR in MVr group is lower than MVR group.

Conclusions: In patients with NIMR, MVr procedure achieves higher survival and fewer complications than surgical MVR. Given these results, MVr surgery should be a priority for NIMR patients.

\section{Introduction}

Mitral regurgitation (MR) is a rather common form of mitral valve (MV) dysfunction. Normal mitral closure depends on the integrity and normal function of five components: the leaflets, annulus, tendons, papillary muscles, and left ventricle. Abnormalities in the structure and function of any one of these five components can lead to MR. Patients with mild MR have only occasional exertional dyspnea. Severe MR (e.g., papillary muscle rupture) quickly leads to acute left heart failure and even cardiac death.

Sever MR commonly requires surgical correction, which is useful for improving prognosis and quality of life of the patients. Traditionally, MV surgery for mitral regurgitation is consisted mainly of mitral valve replacement (MVR) and mitral valve repair (MVr). According to the evidences from many comparative studies, MVr is preferred to MVR and has been increasingly performed since 1980s [1]. Currently, more and more patients are benefiting from successful valve repair operations. There is still a lot of controversy about whether to replace or repair severe MR. Previous surgeons believed that the use of mitral valve repair demonstrated the advantages of a patient population with low surgical risk, few near and long-term adverse events, optimal survival environment and quality of life, and became the preferred surgical treatment modality for mitral valve disease because of its ability to preserve the heart's natural structure intact and achieve optimal cardiac functional reserve. Some surgeons are also hesitant about the durability of mitral valve repair due to conceptual, technical, and experience limitations. Moreover, 
recent data comparing MV repair and replacement failed to demonstrate superiority of MR repair in MR patients [2]. It raises the challenge on MVr superiority.

However, the etiology of MR is varied and may lead to outcome bias after valve surgery. There are many causes of MR, including rheumatic fever, coronary heart disease, congenital valve malformations, and mitral valve degeneration. Considering the complexity of ischemic mitral valve insufficiency, with problems such as the need for revascularization, susceptibility to comorbid ventricular wall tumors or myocardial scars, and severe left heart dysfunction[3], this study mainly selected patients with nonischemic mitral valve insufficiency. We thus performed a meta-analysis comparing clinical results of isolated mitral valve surgery in patients with non-ischemic MR (NIMR).

\section{Method}

\subsection{Standard of systematic reviews}

This study is designed and performed according to the "Transparent reporting of systematic reviews and meta-analyses" (PRISMA) guidelines (see Supplemental material). This systematic review and metaanalysis has been registered with the International Prospective Register of Systematic Reviews (PROSPERO, ID: CRD42018089608).

\subsection{Search strategy}

All studies, including randomized controlled trials (RCTs) and observational comparative studies, of surgical MVR versus surgical MVr enrolling patients with NIMR were identified. Databases including MEDLINE, EMBASE, and the Cochrane Central Register of Controlled Trials were searched through Oct 2020 using Web-based search engines (PubMed and OVID). The search strategies employed a number of free-text keywords as well as controlled vocabulary terms (see Appendix A for actual search strategies).

\subsection{Study selection and data abstraction}

Studies considered for inclusion met the following criteria: the design was a RCT or observational comparative study: the study population was patients with NIMR; patients were assigned to MVR versus $\mathrm{MVr}$; and main outcomes included early (30-day or in-hospital) or late ( $\geq 6$-month including early) allcause mortality. Data regarding detailed inclusion criteria, baseline patient profiles, duration of follow-up, all-cause mortality, and etiology of MR were abstracted (as available) from each individual study.

\subsection{Data extraction and quality assessment}

One investigator (F-X.Z.) used a standardized form to extract the following relevant data and another investigator (C.W.) independently confirmed their accuracy. Disagreement was resolved by discussion with another person (N. Z.). The study quality was assessed using a previously proposed scale (newcastle-ottawa scale) [4,5]. A greater overall score indicated a lower risk of bias; a score of 5 or less (of 9) suggested a high risk of bias. Risk of bias also was evaluated independently by 2 authors. 


\subsection{Statistical analysis}

We conducted a meta-analysis of summary statistics from the individual studies. We generated (1) mean differences (MDs) and 95\% confidence intervals (Cls) using means (with standard deviations) of age, left ventricle ejection fraction (LVEF) in both the MVR and MVr groups and (2) risk (rate) differences (RDs) using rates of women and patients with diabetes, hypertension, heart failure, and New York Heart Association (NYHA) functional class ( $\geq \mathrm{III}$ ) in both groups. HR and $95 \% \mathrm{Cl}$ were used to estimate the effect of survivin expression on survival. If a direct report of $\mathrm{HR}$ and $95 \% \mathrm{Cl}$ was not available, KaplanMeier curves were read using Engauge Digitizer version 4.1, and then the survival data read from KaplanMeier curves were entered in the spreadsheet based on Liu et al[6]. Summary HR (for total survival) and the summary OR (for 30-day survival and re-operation) were directly abstracted from each study. For a study without an available HR, a HR was calculated from Kaplan-Meier curve [7] or summary data using the methods by Parmar et al [8]. Heterogeneity among the included studies was assessed by Cochran's $Q$ statisticc and by calculating the heterogeneity $\left({ }^{2}\right)$. Using reported cut-off values $(>50 \%$ mild, $51-75 \%$ moderate, and $>75 \%$ significant), the random-effects model is used when significant heterogeneity was obtained on analysis; otherwise, the fixed model was applied. Publication bias was assessed visually with the funnel plot and statistically with a mixed-effects Egger's test. All analyses were conducted using Review Manager version 5.3.

\section{Result}

\subsection{Search results}

All 4834 studies were reviewed, and only 20 studies enrolling a total of 21,898 patients with NIMR were included in the final analysis (Table S1 \& Fig. 1) [1, 9-25]. Four studies was retrospective study [10-12, 20], 2 studies are case-control study $[14,19]$, where other studies were prospective cohort study. Two studies exclusively enrolled hypertrophic obstructive cardiomyopathy patients with MR $[12,13]$ and 2 studies exclusively included Marfan syndrome cases with MR [14, 15], whereas 4 studies excluded ischemic MR [9-11, 22]. The other studies enrolled those with degenerative MR. The mean follow-up duration was from 30 days [26] to more than 10 years [12]. When available, prevalence of risk factors of surgery is given in Table S2 separately for each study. These risk factors were: heart failure (New York Heart Association (NYHA) class III or IV, low pre-operative LVEF), prior history of hypertension, diabetes, atrial fibrillation.

\subsection{Quality Assessment}

The quality assessment of 20 studies is shown in Table S3. According to the Newcastle-Ottawa Scale to assess the risk of bias in these studies, 17 studies scored between 6 and 9, indicating high methodologic quality.

\subsection{Patient profiles}


Age Of total 20 articles, 15 studies provided exact values for mean age of two groups. The average age in most of the studies was between 50 and 78 years (Table S1). There was a study reported using younger subjects [14]; while another study used very elderly subjects [11]. A pooled analysis demonstrated that the subjects of MVr group is slightly younger than MVR group (1.92; $[1.74,2.11] ; p=<0.0001$; Supplemental Figure S1).

Woman Of total 20 articles, 14 studies provided exact numbers of women for two groups. Most of the studies had a preponderance of male patients. Rate of women was significantly higher than men in only 2 studies (Table S2) $[13,26]$. Analysis demonstrated that rate of women was lower in the MVr group than MVR group (1.37; [1.28, 1.47]; $p<0.0001$; Supplemental Figure S2).

Pre-operative Cardiac function Of total 20 articles, only 6 studies provided precise values of pre-operative LVEF for two groups, 11 studies supplied the numbers of NIMR patients with NYHA functional class ( $\geq$ III), and 3 studies offered the numbers of NIMR patients with heart failure. Our results proved that there was no difference in number of pre-operative $\operatorname{LVEF}(0.03,[-0.16,0.23] ; p=0.01$, Supplemental Figure $S 3 A)$, or heart failure (1.02, $[0.77,1.35] ; p=0.87$, Supplemental Figure S3C) between two group, but the subjects of NYHA functional class ( $\geq$ III) in MVr group is slightly less than MVR group (1.19, $[1.01,1.41] ; p=$ 0.0009, Supplemental Figure S3B)

Risk factors Of total 20 articles, only 5 studies provided exact numbers of diabetes patients for two groups, 6 studies supplied the numbers of NIMR patients with hypertension, and 11 studies offered the numbers of MR subjects with atrial fibrillation (AF). It was showed that the rates of diabetes $(3.04,[2.03$, 4.54]; $p=0.003$, Supplemental Figure S4A), hypertension $(1.45,[1.33,1.58] ; p<0.00001$, Supplemental Figure S4B) and AF (1.31, $[1.22,1.41] ; p=0.50$, Supplemental Figure S4C) were lower in the MVr group than MVR group.

\subsection{Outcomes}

Early mortality Of total 20 articles, OR for early mortality was available in 12 articles. These studies were not precisely consistent in their definition of early mortality. For the purpose of the current analysis, early outcomes labeled 'early mortality' ( $n=1)$, 'hospital mortality' $(n=2)$, 'operative mortality' $(n=5)$, and '30day mortality' $(n=4)$ were combined under the 'early mortality' label. There was no early mortality among the patients in 1 studies [15]. An unadjusted OR for early mortality was available in 11 studies, only two of which demonstrated a significantly lower early-mortality rate in the MVr group than MVR group [11, 22]. The pooled analysis with these studies showed that summary OR is 2.72 ([2.28, 3.24]; $p<0.00001)$, indicating that the MVR group has significantly increased risk of early dying compared to the MVr group (Fig. 2). Studies were subgroup according to the etiology of MR, and 7 of these studies are about degenerative MR. The heterogeneity test was not significant $\left(p=0.09, \mathrm{I}^{2}<50 \%\right)$ for degenerative subgroup, as well as for all of the included studies, suggesting that there was no clear evidence of a major discrepancy among the OR for the studies analyzed. 
Late survival Of total 20 articles, HR for late mortality was available in 10 articles, 4 of which offered the adjusted HR $[1,17,23,27]$. HR for 20 years survival was offered in two studies [1, 17], one study provided 6 years survival data [24], one study provided 5 years survival data [20], while HR for about ten years survival was available in five articles $[12,14,18,23,25,27]$. A pooled analysis indicated statistically much higher late-mortality rate in MVR group than MVr group (1.81, [1.59, 2.07]; $p=0.56$, Fig. 3). Studies were subgroup according to the etiology of MR, and 7 of these studies are about degenerative MR. The heterogeneity test was not significant $\left(p>0.10, l^{2}<50 \%\right)$ for degenerative subgroup, as well as for all of the included studies, suggesting that there was no clear evidence of a major discrepancy among the hazard ratios for the studies analyzed.

Reoperation Out of the articles reviewed, 9 articles provided information to allow determination of the reoperative OR for mitral valve replacement relative to repair. The results demonstrated that the risk of reoperation is higher in MVR group than in MVr group (1.59; [1.36, 1.86]; $p=0.22$; Fig. 4).

Complications Major complications of MV surgery in reviewed studies are post-operative MR (including residual or recurrent MR), thromboembolism, heart failure, infective endocarditis. From all of the reviewed articles, information for determining the hazard ratio for development of these complications is insufficient.

The severe mitral regurgitation after operation were analyzed. Out of the articles reviewed, only four articles provided exact numbers of post-operative MR in two groups. Results demonstrated that the incidence rate of post-operative MVr group is lower than MVR group (1.43; $[1.13,1.82] ; p=0.01$; Figure S5).

Besides, other complications were studied in only two articles [22, 24]. Both of them showed beneficial effects from repair compared to replacement for thromboembolism and heart failure. One study [22] demonstrated that more patients had infective endocarditis in the MVR group than MVr group, while another study [24] demonstrated that the incidence rate of infective endocarditis in two group is comparable.

\subsection{Publication bias}

Inspection of the funnel plot (Fig. 5) did not show significant asymmetry for early and late mortality. These results suggest that publication bias was not a significant influencing factor.

\section{Discussion}

The current meta-analysis is an attempt to pool basic available information on the outcome experience of the two treatment methods for NIMR, specifically defined as mitral valve repair or mitral valve replacement. All of the studies included comprised 21,898 patients (20 studies). We demonstrate that statistically significant early and late survival benefit for patients who had undergone MVr, while MVr also achieves lower rates of re-operation and post-operative MR than surgical MV replacement. However, there 
is insufficient information for determining the hazard ratio of other surgery complications. A few articles indicated that the post-operative risk of thromboembolism and heart failure was lower for repairs compared to replacements.

It is generally regarded that the outcome after $\mathrm{MVr}$ is better than that after MVR, and valve repair operation has become the first choice in patients with mitral valve diseases $[28,29]$. In agreement with previously published data, the early and late mortality of NIMR in the MVr subgroup significantly favored the repair group. Moreover, the present findings should be interpreted with caution, because of higher risk profiles (high rates of diabetes and AF) in the MVr than surgical MVR group. Previous study proved that diabetes and AF are associated with significantly worse outcomes after valve operations [30, 31]. Higher survival despite higher risk profiles suggests that the MVr procedure achieves much more survival than surgical MVR for NIMR.

Different etiologies can affect different mitral apparatus and produce various pathologic changes and outcomes [32]. Common causes of MR are congenital cleft mitral valve, rheumatic heart disease, mitral valve prolapse, infective endocarditis, rupture of chordae tendineae, Marfan syndrome, hypertrophic cardiomyopathy, endocardial fibrosis, and ischemic heart disease [33]. This review summarize degenerative, hypertrophic, Marfan and mixed mitral valve regurgitation. Most of these studies included a cohort of patients with degenerative subjects. Mitral valve repair rather than replacement exhibited a survival advantage in this sub-group. More articles are needed for etiologic analyze.

In this review, the risk of re-operation is higher in MVR group. Theoretically, patients who had unsuccessful valve repair should have a worse outcome than those who underwent direct mitral valve replacement due to the increased complexity of surgery and longer cardiopulmonary bypass time [34, 35]. Knowledge of the risk factors for the failure of MV is very important to reduce the rate of reoperation. The several reasons for re-operation included technical mistakes and valve-related causes (e.g. infection, progression of disease, and thrombosis). The mainly reason in patients with NIMR are post-operative MR, including residual or recurrent MR [36]. In this review, the incidence rate of post-operative MR is higher in MVR group. The main mechanism of recurrent regurgitation after MV repair is progressive degeneration. Surgical repair procedures differed in some details, according to method of annuloplasty (suture vs. ring), type of ring annuloplasty (flexible or rigid), and chordal modification (transposition, shortening and replacement) [28]. The variations could help to improve the effect of surgery and minimize valvular failure. Zhou et al identified the following factors as having an influence on the durability of repair for degenerative mitral valve disease: age $<60$ years, ring size $(\mathrm{mm}) /$ body surface area $\left(\mathrm{m}^{2}\right) \geq 19.0$, absence of a prosthetic ring and residual mitral regurgitation $(\geq 1 / 4)$ at the end of surgery [20]. The selection of a surgical procedure (repair vs. replacement) is a multifactorial process influenced by surgeon, patient and institution. All these above will be helpful when deciding whether to accept the repair or replacement.

Limitations: There is no RCT study cited, the results are based on data pooled from retrospective study, case-control study and prospective cohort study. Hendrix' study which contain 12,043 subjects, had too much weight in the analysis of multiple results [26]. Moreover, most study collected subjects with 
degenerative NIMR. Therefore, potential biases must be great because of different type, weight and etiology of study; the results should be always interpreted with caution. Moreover, more studies are needed to supply sufficient information to quantify the effect of etiology and the HR for surgery complications.

\section{Conclusions}

In conclusion, surgery for NIMR had lower 30-day mortality and higher survival for repair than replacement despite risk profiles (higher rate of diabetes and AF). And lower rates of re-operation and post-operative MR is observed in repair group of non-ischemic mitral valve. However, etiology-related differences in the risk of re-operation remain uncertain and further studies or trials would be needed. The results of this systematic review and meta-analysis could support patients and doctors in the mitral valve surgery choice and can be used to predict outcomes of INMR patient.

\section{Abbreviations}

confidence intervals (Cls), hazard ratios (HRs), left ventricle ejection fraction (LVEF), Mitral regurgitation (MR), mitral valve replacement (MVR) $\square$ mitral valve repair (MVr), non-ischemic MR (NIMR), mean differences (MDs), New York Heart Association (NYHA), randomized controlled trials (RCTs), risk (rate) differences (RDs), odds ratios (ORs).

\section{Declarations}

\section{Author contributions}

Fengxiao zhang designed the study. Puliang Yu凶Cheng Wang and Fengxiao zhang screened studies and extracted data. Disagreements were resolved by discussion with Ning zhao. Cheng Wang and Puliang Yu did the statistical analyses and prepared figures. Puliang Yu, Cheng Wang, Ning Zhao, Fengxiao Zhang reviewed the results, interpreted data, and wrote the manuscript. All authors saw and approved the final version of the paper.

\section{Acknowledgements}

This work was supported by National Natural Science Foundation of China [number 81400303, 51705378 and 81700332], and Postdoctoral Sustentation Fund of China [number 2017M622532].

\section{Ethics declarations}

\section{Ethics approval and consent to participate}

The Ethical Committee of the Tongji Hospital, Tongji Medical College, Huazhong University of Science and Technology, Wuhan, China, reviewed and approved our study protocol. Since the study is a metaanalysis, informed consent was waived. 


\section{Consent for publication}

Not applicable.

\section{Conflicts of interest}

The authors have nothing to disclose.

\section{Availability of data and materials}

The datasets used and analyzed during the current study are available from the corresponding author on reasonable request.

\section{References}

1. Lazam S, Vanoverschelde JL, Tribouilloy C, Grigioni F, Suri RM, Avierinos JF, et al. Twenty-Year Outcome After Mitral Repair Versus Replacement for Severe Degenerative Mitral Regurgitation: Analysis of a Large, Prospective, Multicenter, International Registry. Circulation. 2017;135(5):410-22. Epub 2016/12/03. doi: 10.1161/CIRCULATIONAHA.116.023340. PubMed PMID: 27899396.

2. Altarabsheh SE, Deo SV, Dunlay SM, Erwin PJ, Obeidat YM, Navale S, et al. Meta-Analysis of Usefulness of Concomitant Mitral Valve Repair or Replacement for Moderate Ischemic Mitral Regurgitation With Coronary Artery Bypass Grafting. Am J Cardiol. 2017;119(5):734-41. Epub 2017/01/23. doi: 10.1016/j.amjcard.2016.11.024. PubMed PMID: 28109559.

3. Michler RE, Smith PK, Parides MK, Ailawadi G, Thourani V, Moskowitz AJ, et al. Two-Year Outcomes of Surgical Treatment of Moderate Ischemic Mitral Regurgitation. The New England journal of medicine. 2016;374(20):1932-41. Epub 2016/04/05. doi: 10.1056/NEJMoa1602003. PubMed PMID: 27040451; PubMed Central PMCID: PMCPMC4908820.

4. Berndt J, Kloting N, Kralisch S, Kovacs P, Fasshauer M, Schon MR, et al. Plasma visfatin concentrations and fat depot-specific mRNA expression in humans. Diabetes. 2005;54(10):2911-6. Epub 2005/09/28. PubMed PMID: 16186392.

5. Kim DH, Kim C, Ding EL, Townsend MK, Lipsitz LA. Adiponectin levels and the risk of hypertension: a systematic review and meta-analysis. Hypertension. 2013;62(1):27-32. doi:

10.1161/HYPERTENSIONAHA.113.01453. PubMed PMID: 23716587; PubMed Central PMCID: PMC3729220.

6. Liu JL, Zhang XJ, Zhang Z, Zhang AH, Wang W, Dong JH. Meta-analysis: prognostic value of survivin in patients with hepatocellular carcinoma. PLoS One. 2013;8(12):e83350. Epub 2014/01/05. doi: 10.1371/journal.pone.0083350. PubMed PMID: 24386184; PubMed Central PMCID: PMCPMC3873280.

7. Tierney JF, Stewart LA, Ghersi D, Burdett S, Sydes MR. Practical methods for incorporating summary time-to-event data into meta-analysis. Trials. 2007;8:16. Epub 2007/06/09. doi: 10.1186/1745-62158-16. PubMed PMID: 17555582; PubMed Central PMCID: PMCPMC1920534. 
8. Parmar MK, Torri V, Stewart L. Extracting summary statistics to perform meta-analyses of the published literature for survival endpoints. Stat Med. 1998;17(24):2815-34. Epub 1999/01/28. PubMed PMID: 9921604.

9. Le Tourneau T, de Groote P, Millaire A, Foucher C, Savoye C, Pigny P, et al. Effect of mitral valve surgery on exercise capacity, ventricular ejection fraction and neurohormonal activation in patients with severe mitral regurgitation. J Am Coll Cardiol. 2000;36(7):2263-9. Epub 2000/12/29. PubMed PMID: 11127471.

10. Senechal M, MacHaalany J, Bertrand OF, O'Connor K, Parenteau J, Dubois-Senechal IN, et al. Predictors of left ventricular remodeling after surgical repair or replacement for pure severe mitral regurgitation caused by leaflet prolapse. Am J Cardiol. 2013;112(4):567-73. Epub 2013/05/21. doi: 10.1016/j.amjcard.2013.04.024. PubMed PMID: 23683949.

11. DiGregorio V, Zehr KJ, Orszulak TA, Mullany CJ, Daly RC, Dearani JA, et al. Results of mitral surgery in octogenarians with isolated nonrheumatic mitral regurgitation. Ann Thorac Surg. 2004;78(3):807-13; discussion 13-4. Epub 2004/09/01. doi: 10.1016/j.athoracsur.2004.03.041. PubMed PMID: 15336996.

12. Hong JH, Schaff HV, Nishimura RA, Abel MD, Dearani JA, Li Z, et al. Mitral Regurgitation in Patients With Hypertrophic Obstructive Cardiomyopathy: Implications for Concomitant Valve Procedures. J Am Coll Cardiol. 2016;68(14):1497-504. Epub 2016/10/01. doi: 10.1016/j.jacc.2016.07.735. PubMed PMID: 27687190.

13. Vassileva CM, Boley T, Markwell S, Hazelrigg S. Mitral valve repair is underused in patients with hypertrophic obstructive cardiomyopathy. Heart Surg Forum. 2011;14(6):E376-9. Epub 2011/12/15. doi: 10.1532/HSF98.20111067. PubMed PMID: 22167765.

14. Helder MR, Schaff HV, Dearani JA, Li Z, Stulak JM, Suri RM, et al. Management of mitral regurgitation in Marfan syndrome: Outcomes of valve repair versus replacement and comparison with myxomatous mitral valve disease. J Thorac Cardiovasc Surg. 2014;148(3):1020-4; discussion 4. Epub 2014/08/19. doi: 10.1016/j.jtcvs.2014.06.046. PubMed PMID: 25129593.

15. Bozbuga N, Erentug V, Kirali K, Akinci E, Yakut C. Surgical management of mitral regurgitation in patients with Marfan syndrome. J Heart Valve Dis. 2003;12(6):717-21. Epub 2003/12/09. PubMed PMID: 14658812.

16. Shafii AE, Gillinov AM, Mihaljevic T, Stewart W, Batizy LH, Blackstone EH. Changes in left ventricular morphology and function after mitral valve surgery. Am J Cardiol. 2012;110(3):403-8 e3. Epub 2012/04/27. doi: 10.1016/j.amjcard.2012.03.041. PubMed PMID: 22534055; PubMed Central PMCID: PMCPMC4717321.

17. Coutinho GF, Correia PM, Branco C, Antunes MJ. Long-term results of mitral valve surgery for degenerative anterior leaflet or bileaflet prolapse: analysis of negative factors for repair, early and late failures, and survival. Eur J Cardiothorac Surg. 2016;50(1):66-74. Epub 2016/01/23. doi: 10.1093/ejcts/ezv470. PubMed PMID: 26792923. 
18. Zalaquett R, Scheu M, Campla C, Moran S, Irarrazaval MJ, Becker P, et al. [Long-term results of repair versus replacement for degenerative mitral valve regurgitation]. Rev Med Chil. 2005;133(10):1139-46. Epub 2005/12/13. doi: /S0034-98872005001000002. PubMed PMID: 16341364.

19. Pandis D, Grapsa J, Athanasiou T, Punjabi P, Nihoyannopoulos P. Left ventricular remodeling and mitral valve surgery: prospective study with real-time 3-dimensional echocardiography and speckle tracking. J Thorac Cardiovasc Surg. 2011;142(3):641-9. Epub 2011/02/01. doi:

10.1016/j.jtcvs.2010.11.030. PubMed PMID: 21277588.

20. Zhou YX, Leobon B, Berthoumieu P, Roux D, Glock Y, Mei YQ, et al. Long-term outcomes following repair or replacement in degenerative mitral valve disease. Thorac Cardiovasc Surg. 2010;58(7):41521. Epub 2010/10/06. doi: 10.1055/s-0029-1240925. PubMed PMID: 20922625.

21. Grapsa J, Dawson D, Pandis D, Ntalarizou E, Cheung WS, Efthimiadis I, et al. Mitral valve repair results in better right ventricular remodelling than valve replacement for degenerative mitral regurgitation: a three-dimensional echocardiographic study. Hellenic J Cardiol. 2012;53(4):279-86. Epub 2012/07/17. PubMed PMID: 22796815.

22. Gramaglia B, Imazio M, Checco L, Villani M, Morea M, Di Summa M, et al. Mitral valve prolapse. Comparison between valvular repair and replacement in severe mitral regurgitation. J Cardiovasc Surg (Torino). 1999;40(1):93-9. Epub 1999/04/30. PubMed PMID: 10221393.

23. Gillinov AM, Faber C, Houghtaling PL, Blackstone EH, Lam BK, Diaz R, et al. Repair versus replacement for degenerative mitral valve disease with coexisting ischemic heart disease. $J$ Thorac Cardiovasc Surg. 2003;125(6):1350-62. Epub 2003/06/28. PubMed PMID: 12830055.

24. Lee EM, Shapiro LM, Wells FC. Superiority of mitral valve repair in surgery for degenerative mitral regurgitation. Eur Heart J. 1997;18(4):655-63. Epub 1997/04/01. PubMed PMID: 9129898.

25. Mohty D, Orszulak TA, Schaff HV, Avierinos JF, Tajik JA, Enriquez-Sarano M. Very long-term survival and durability of mitral valve repair for mitral valve prolapse. Circulation. 2001;104(12 Suppl 1):11-17. Epub 2001/09/25. PubMed PMID: 11568020.

26. Hendrix RJ, Bello RA, Flahive JM, Kakouros N, Aurigemma GP, Keaney JF, et al. Mitral Valve Repair Versus Replacement in Elderly With Degenerative Disease: Analysis of the STS Adult Cardiac Surgery Database. Ann Thorac Surg. 2019;107(3):747-53. Epub 2019/01/08. doi: 10.1016/j.athoracsur.2018.09.018. PubMed PMID: 30612990.

27. Hata M, Zittermann A, Hakim-Meibodi K, Borgermann J, Gummert J. Minimally invasive mitral valve repair or replacement for degenerative mitral regurgitation. Interact Cardiovasc Thorac Surg. 2019;28(4):575-80. Epub 2018/11/27. doi: 10.1093/icvts/ivy305. PubMed PMID: 30476075.

28. Shuhaiber J, Anderson RJ. Meta-analysis of clinical outcomes following surgical mitral valve repair or replacement. Eur J Cardiothorac Surg. 2007;31(2):267-75. Epub 2006/12/19. doi: 10.1016/j.ejcts.2006.11.014. PubMed PMID: 17175161.

29. Kouris N, Ikonomidis I, Kontogianni D, Smith P, Nihoyannopoulos P. Mitral valve repair versus replacement for isolated non-ischemic mitral regurgitation in patients with preoperative left 
ventricular dysfunction. A long-term follow-up echocardiography study. Eur J Echocardiogr. 2005;6(6):435-42. Epub 2005/11/19. doi: 10.1016/j.euje.2005.01.003. PubMed PMID: 16293530.

30. Halkos ME, Kilgo P, Lattouf OM, Puskas JD, Cooper WA, Guyton RA, et al. The effect of diabetes mellitus on in-hospital and long-term outcomes after heart valve operations. Ann Thorac Surg. 2010;90(1):124-30. Epub 2010/07/09. doi: 10.1016/j.athoracsur.2010.03.111. PubMed PMID: 20609762.

31. Jovin A, Oprea DA, Jovin IS, Hashim SW, Clancy JF. Atrial fibrillation and mitral valve repair. Pacing Clin Electrophysiol. 2008;31(8):1057-63. Epub 2008/08/08. doi: 10.1111/j.1540-8159.2008.01135.x. PubMed PMID: 18684264.

32. Meyer MA, von Segesser LK, Hurni M, Stumpe F, Eisa K, Ruchat P. Long-term outcome after mitral valve repair: a risk factor analysis. Eur J Cardiothorac Surg. 2007;32(2):301-7. Epub 2007/06/15. doi: 10.1016/j.ejcts.2007.05.008. PubMed PMID: 17561410.

33. Maganti K, Rigolin VH, Sarano ME, Bonow RO. Valvular heart disease: diagnosis and management. Mayo Clin Proc. 2010;85(5):483-500. Epub 2010/05/04. doi: 10.4065/mcp.2009.0706. PubMed PMID: 20435842; PubMed Central PMCID: PMCPMC2861980.

34. Salis S, Mazzanti VV, Merli G, Salvi L, Tedesco CC, Veglia F, et al. Cardiopulmonary bypass duration is an independent predictor of morbidity and mortality after cardiac surgery. J Cardiothorac Vasc Anesth. 2008;22(6):814-22. Epub 2008/10/25. doi: 10.1053/j.jvca.2008.08.004. PubMed PMID: 18948034.

35. Wang Z, Zhou C, Gu H, Zheng Z, Hu S. Mitral valve repair versus replacement in patients with rheumatic heart disease. J Heart Valve Dis. 2013;22(3):333-9. Epub 2013/10/25. PubMed PMID: 24151759.

36. Obata A, Yoshikawa J, Yoshida K, Akasaka T, Yamaura Y, Shakudo M, et al. [Residual, recurrent mitral regurgitation after mitral valve reconstruction: differences in lesion and operation method]. J Cardiol. 1994;24(4):311-6. Epub 1994/07/01. PubMed PMID: 8057243.

\section{Appendix}

Appendix $A$ is not available with this version

\section{Figures}




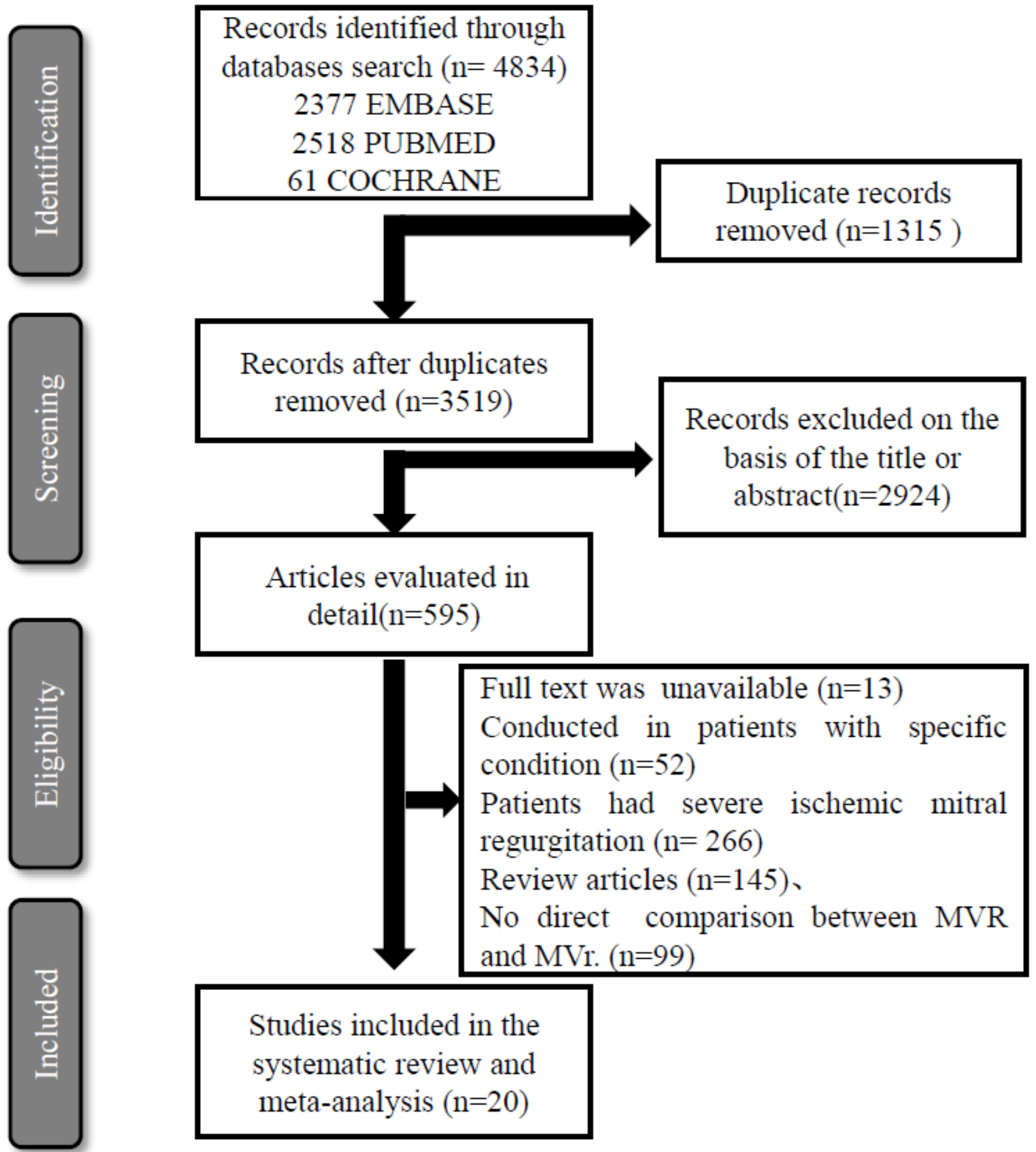

Figure 1

Flowchart depicting study selection for meta-analysis. 
MVR MVr Odds Ratio Odds Ratio

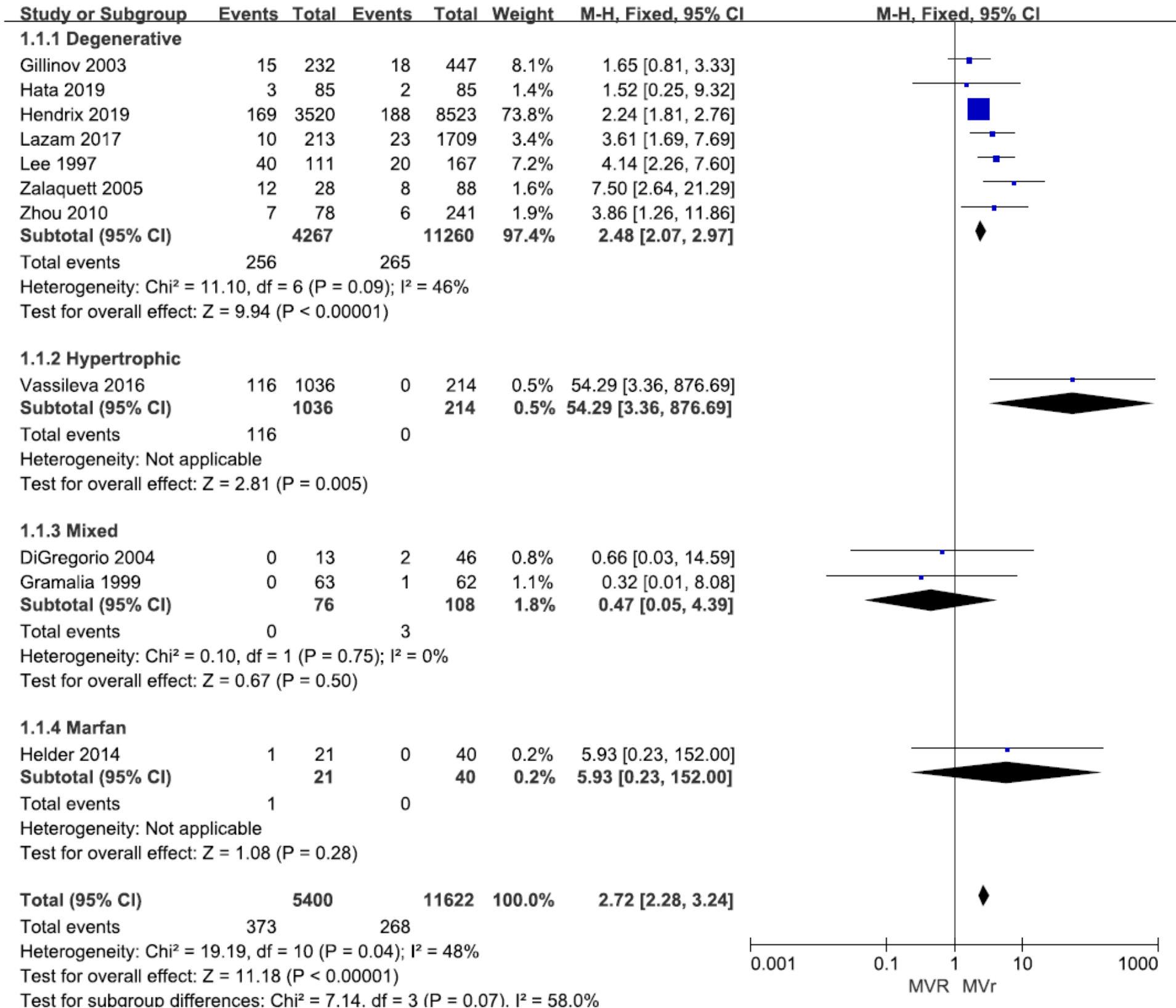

\section{Figure 2}

Forest plot of OR of early mortality for MVR versus MVr. 


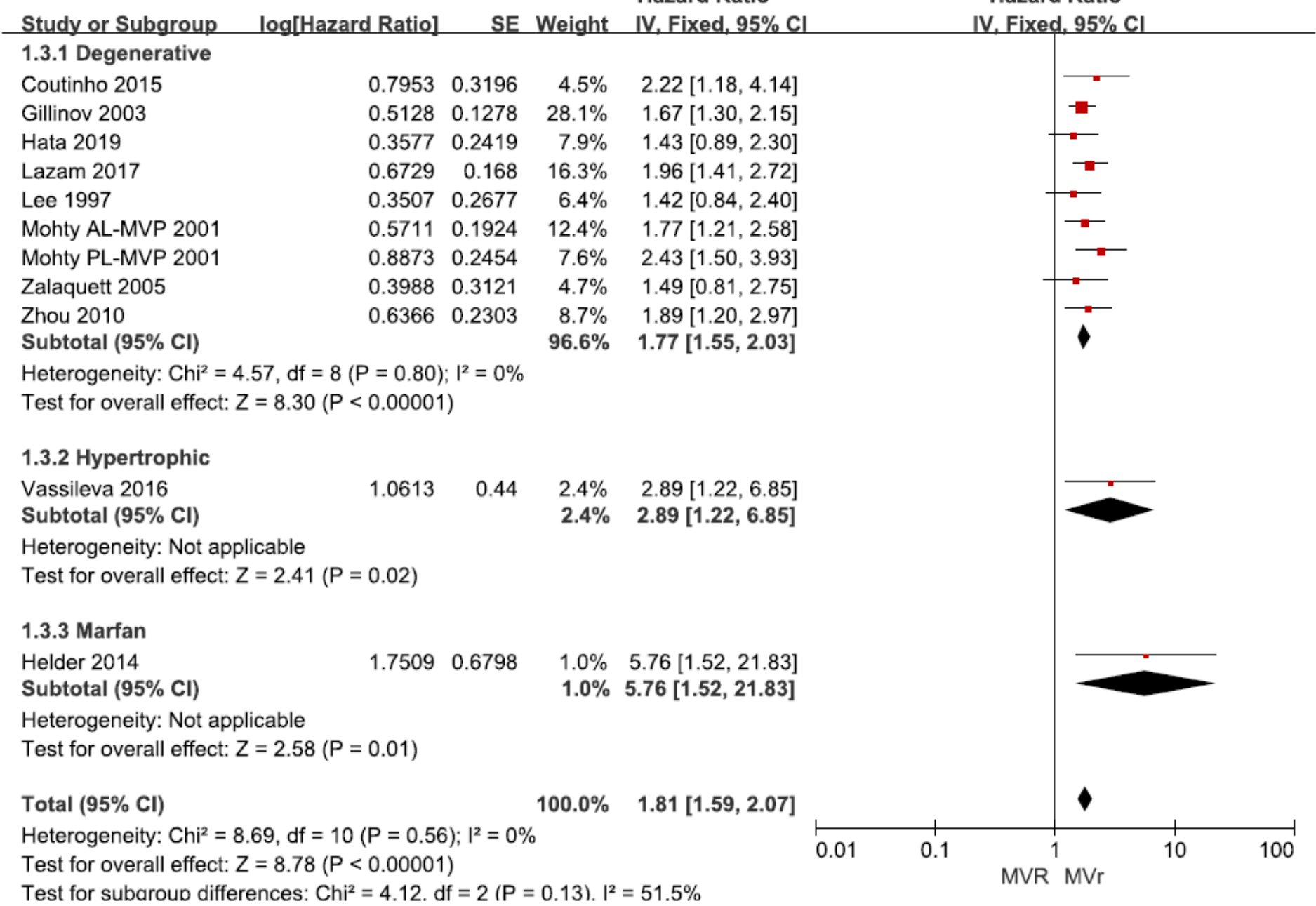

\section{Figure 3}

Forest plot of HR of late mortality for MVR versus MVr.

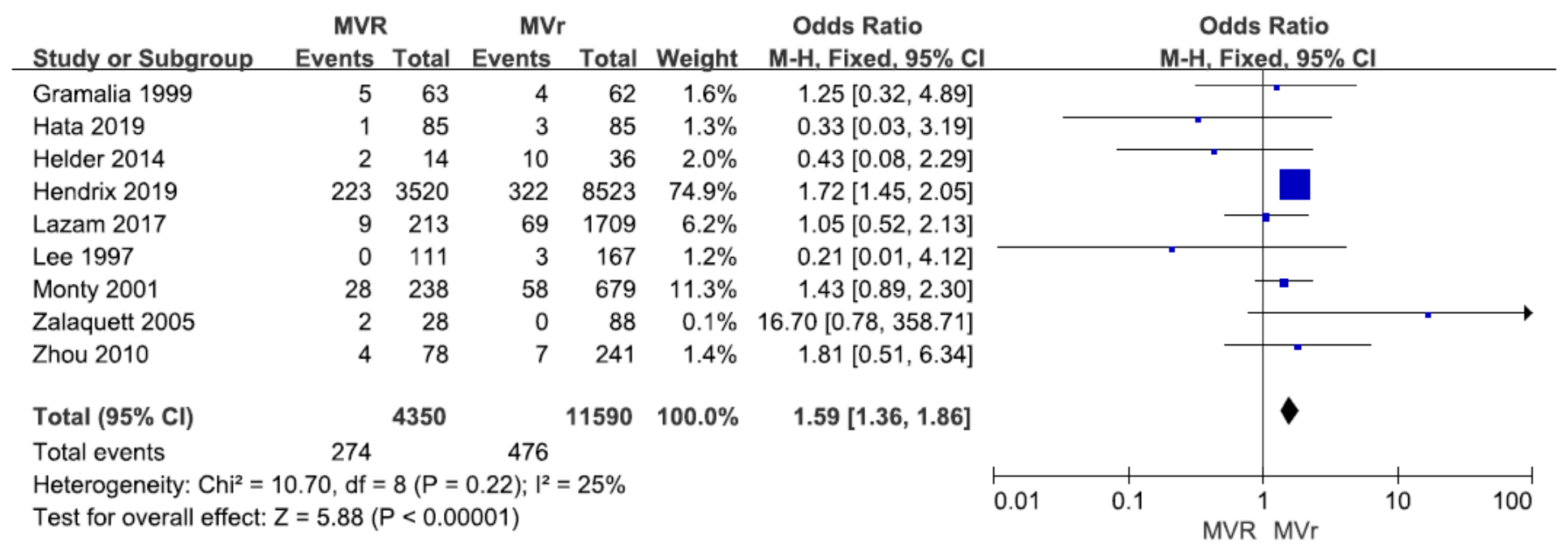

\section{Figure 4}


Forest plot of OR of re-operation for MVR versus MVr.
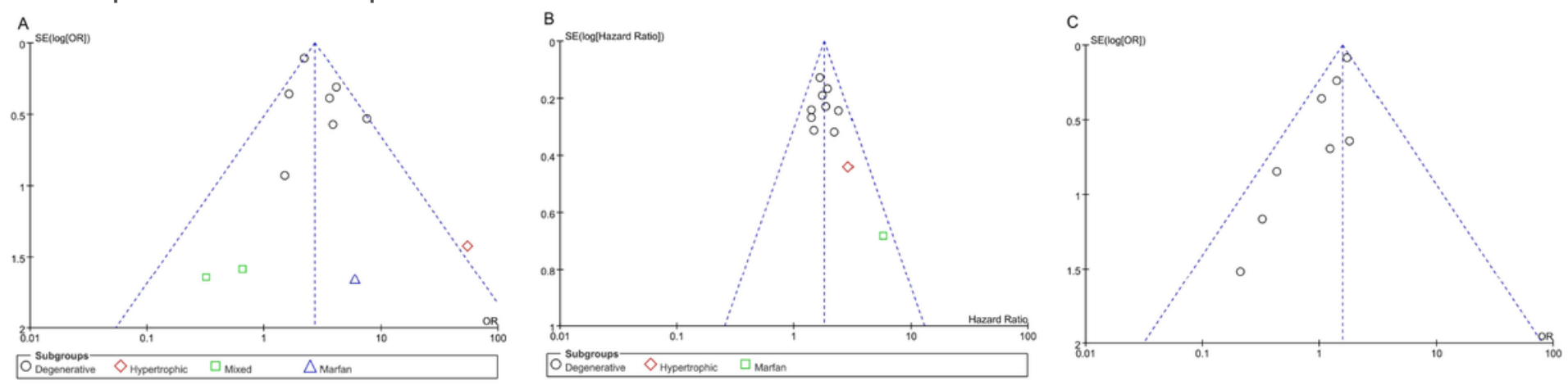

Figure 5

Funnel plot of early (A) and late (B) mortality.

\section{Supplementary Files}

This is a list of supplementary files associated with this preprint. Click to download.

- tables20210224.doc

- figureS1ageForestplot.pdf

- figures4.pdf

- figureS2womanForestplot.pdf

- figureS3.pdf

- figureS5MRForestplot.pdf 